\title{
UPTAKE OF 2'-AMINO-2'-DEOXYGUANOSINE BY ESCHERICHIA COLI AND ITS COMPETITION BY GUANOSINE
}

\author{
Toshihide Nakanishi, Fusao Tomita and Akira Furuya \\ Tokyo Research Laboratory, Kyowa Hakko Kogyo Co., Ltd., \\ Machida, Tokyo, Japan
}

(Received for publication May 30, 1977)

\begin{abstract}
The antibacterial activity of a new nucleoside antibiotic, $2^{\prime}$-amino-2'-deoxyguanosine ( $2 \mathrm{AG})$, is reversed by guanosine and other purine nucleosides. $2 \mathrm{AG}$ is apparently taken up by $E$. coli by a mechanism different from that of guanosine; guanosine inhibits this uptake non-competitively. Insensitive E. coli strains and the resistant mutant obtained from the sensitive strain also took up $2 \mathrm{AG}$.
\end{abstract}

We reported previously ${ }^{1,2,3)}$ that a strain of Enterobacter cloacae produces a novel aminonucleoside antibiotic, 2'-amino-2'-deoxyguanosine (2AG), the structure of which is shown in Fig. 1. This compound inhibits only some strains of Escherichia coli, shows antitumor activity against sarcoma 180 in mouse, and is cytotoxic to HeLa cells.

Many nucleoside antibiotics have been described $^{43}$ and all such purine nucleosides are adenosine analogs. $2 \mathrm{AG}$ is the first guanosine analog and the first nucleoside containing 2-amino-

Fig. 1. 2'-Amino-2'-deoxyguanosine (2AG) 2-deoxyribose found in nature. $2 \mathrm{AG}$ has been synthesized chemically by IKEHARA et al. ${ }^{5}$ ) and HoBBS et al. ${ }^{6)}$

In this paper, we describe the reversal of antibacterial activity of $2 \mathrm{AG}$ by guanosine, the inhibition

of incorporation of $2 \mathrm{AG}$ into the cell by guanosine, and the lack of difference in uptake by sensitive and resistant strains.

\section{Materials and Methods}

Microorganisms. Escherichia coli KY 3591, K-12, KY 8232 and other strains were from our laboratory collection. Strain KY 3591 is the most sensitive to 2AG whereas strain K-12 is one of the insensitive strains. Strain KY 8232 is a purine-requiring mutant of K-12.

Media and culture conditions. Wild-type strains were grown in a medium having the following composition: $\mathrm{KH}_{2} \mathrm{PO}_{4}, 13.6 \mathrm{~g}$; $\left(\mathrm{NH}_{4}\right)_{2} \mathrm{SO}_{4}, 2 \mathrm{~g}$; glucose, $3 \mathrm{~g}$; Casamino acids (Difco), $3 \mathrm{~g} ; \mathrm{MgCl}_{2}$, $95 \mathrm{mg}$; $\mathrm{FeSO}_{4} \cdot 7 \mathrm{H}_{2} \mathrm{O}, 0.5 \mathrm{mg}$; thiamine- $\mathrm{HCl}, 0.1 \mathrm{mg}$ per liter of water. For the growth of the purinerequiring strain, $100 \mathrm{mg}$ of adenine per liter were added. All cultures were incubated at $30^{\circ} \mathrm{C}$ with shaking. For the agar diffusion assay of antibacterial activity, medium containing $0.8 \%$ agar was used and incubated at $30^{\circ} \mathrm{C}$ for 16 hours.

Determination of cell growth. The growth of cells was automatically recorded with Bio-photorecorder TN-112M (Toyo Kagaku Sangyo) or intermittently measured using a colorimeter (ANA-7A, Tokyo Koden) equipped with a red filter.

Paper chromatography. Ascending paper chromatography was carried out with Toyo Roshi 
No. 51A filter paper. Water ( $\mathrm{pH} 10)$ was used as solvent.

Measurement of guanosine and guanine. The concentration of guanosine and guanine in the medium was determined by scanning paper chromatogram with the Dual-Wavelength TLC Scanner CS 900 (Shimazu).

Measurement of radioactivity. The radioactivity of aqueous samples was determined in dioxane scintillation fluid containing $50 \mathrm{~g}$ of naphthalene, $10 \mathrm{~g}$ of 2,5-diphenyloxazole (PPO) and $0.25 \mathrm{~g}$ of 2,2'-p-phenylene-bis-(5-phenyloxazole) (POPOP) per liter of dioxane with a Packard Tricarb Scintillator. The radioactivity of Millipore filters was counted in toluene scintillation fluid containing $4 \mathrm{~g}$ of PPO and $0.1 \mathrm{~g}$ of POPOP per liter of toluene.

Incorporation of radioactive compounds into cells. After the addition of radioactive compounds, $0.5 \mathrm{ml}$ samples were removed at intervals. They were immediately filtered through HA Millipore filters $(0.45 \mu)$ and washed with $15 \mathrm{ml}$ of fresh medium without glucose. The filters were dried and counted in vials containing toluene scintillation fluid.

Preparation of $2 \mathrm{AG}-8-{ }^{3} \mathrm{H}$. Preliminary experiment with deuterium oxide $\left(\mathrm{D}_{2} \mathrm{O}\right)$. The method of EIDINOFF and $\mathrm{KNOLL}^{\text {7) }}$ was employed with some modifications. A preliminary experiment was carried out with $\mathrm{D}_{2} \mathrm{O}$ in order to find a suitable condition for tritiation of $2 \mathrm{AG}$. The reaction mixture contained $5 \mathrm{mg}$ of reduced platinum, $0.5 \mathrm{ml}$ of $\mathrm{D}_{2} \mathrm{O}(99.75 \%)$ and $20 \mathrm{mg}$ of $2 \mathrm{AG}$. The following conditions were examined; (1) a tube was sealed immediately, (2) after freezing the reaction mixture, the tube was sealed off under vacuum, (3) after displacing the air by nitrogen gas, the tube was sealed. These sealed tubes were heated at $100^{\circ} \mathrm{C}$ for 18 hours. After the platinum was removed by centrifugation, deuterochloric acid was added to a concentration of $5 \%$ and the tubes were subjected to proton nuclear magnetic resonance spectroscopy in order to confirm the deuterium-substitution of the proton at position- 8 of guanine. In no case was the signal of $8-{ }^{1} \mathrm{H}$ detected at $9.4 \mathrm{ppm}$, other proton signals were not affected by this treatment. These results showed that complete deuterium-substitution at $8-^{1} \mathrm{H}$ was specifically obtained. When these reaction mixtures were developed with paper chromatography, some guanine was detected. No UV-absorbing spot was detected other than those of $2 \mathrm{AG}$ and guanine. The amount of guanine produced by side reactions under each condition was (1) $17.4 \%$, (2) $13.5 \%$ and (3) $15.3 \%$, respectively. These results showed that the different conditions affected the displacement reaction only very little. We adopted condition (3) for tritiation by considering the safety of the operation.

Tritiation of 2AG. Using the above condition, except for $0.5 \mathrm{ml}$ of tritium oxide $(0.5 \mathrm{Ci} / \mathrm{ml})$ replacing $\mathrm{D}_{2} \mathrm{O}$, the tritiation reaction was carried out. After the reaction, $0.5 \mathrm{ml}$ of $0.1 \mathrm{~N}$ hydrochloric acid was added and the supernatant solution was poured into $30 \mathrm{ml}$ of acetone. The precipitates were washed with acetone twice. Dissolving the precipitates in one $\mathrm{ml}$ of $0.1 \mathrm{~N}$ hydrochloric acid, the same procedure as above was repeated twice in order to remove tritium oxide and exchangeable tritium in $2 \mathrm{AG}$ (i.e. $-\mathrm{O}^{3} \mathrm{H}$ and $-\mathrm{N}^{3} \mathrm{H}_{2}$ ). In order to eliminate degradation products, the reaction mixture was passed through the column of $10 \mathrm{ml}$ of Dowex $50 \times 8\left(\mathrm{NH}_{4}{ }^{+}\right.$form $)$. Thirteen $\mathrm{mg}$ of $2 \mathrm{AG}$ were obtained with a specific activity of $6.4 \mathrm{mCi} / \mathrm{m}$ mole. No spot other than $2 \mathrm{AG}$ was detected by paper chromatography and the isotopic purity was confirmed.

Chemicals. 2'-Amino-2'-deoxyadenosine was obtained from Dr. M. IKEHARA of Osaka University. Guanosine- $\mathrm{U}_{-14}^{14} \mathrm{C}(0.4 \mathrm{Ci} / \mathrm{m}$ mole $)$ and tritium oxide $(0.5 \mathrm{Ci} / \mathrm{ml})$ were purchased from New England Nuclear. Purine related compounds, chloramphenicol, penicillin $\mathrm{G}$, mitomycin $\mathrm{C}$ and 5 -fluorouracil were products of Kyowa Hakko Kogyo Co. Ltd.

\section{Results}

Antibacterial Activity of $2 \mathrm{AG}$

In a previous study, antibacterial activity of $2 \mathrm{AG}$ was detected only for one strain (KY 8323) of E. coli among three strains tested. ${ }^{3)}$ We further examined additional strains of E. coli in order to determine the antibacterial spectrum of 2AG. Among 20 strains tested, strain KY 3591 was the only strain sensitive to $2 \mathrm{AG}$ which gave a clear growth-inhibition zone. Other strains including $\mathrm{K}-12$, B 
Fig. 2. Growth of E. coli in the presence of $2 \mathrm{AG}$

To exponentially growing cells of $E$. coli, $2 \mathrm{AG}$ was added at various concentrations. The incubation and measurement of bacterial growth were carried out in the Bio-photorecorder TN-112 (Toyo Kagaku Sangyo).

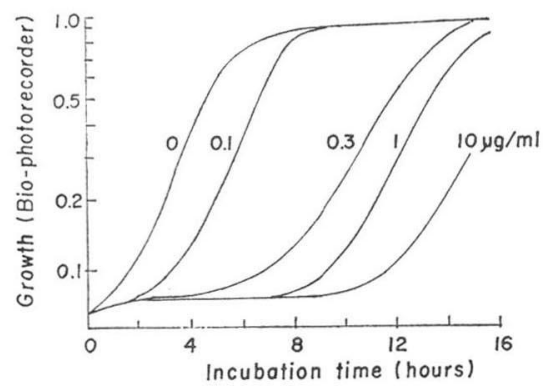

Fig. 4. Reversal of antibacterial activity of $2 \mathrm{AG}$ by purine related compounds

Incubation of E. coli KY 3591 was performed in the Bio-photorecorder. In the presence of $2 \mathrm{AG}$ $(0.035 \mathrm{~mm})$, purine related compounds were added at $0.35 \mathrm{~mm}$.

1), without $2 \mathrm{AG} ; 2$ ), guanosine; 3), adenosine; 4), inosine; 5), deoxyguanosine; 6), deoxyadenosine; 7), 5'-adenylic acid; 8), 5'-guanylic acid; 9), none, guanine, adenine, hypoxanthine, xanthine, xanthosine, 5'-inosinic acid or 5'-xanthylic acid.

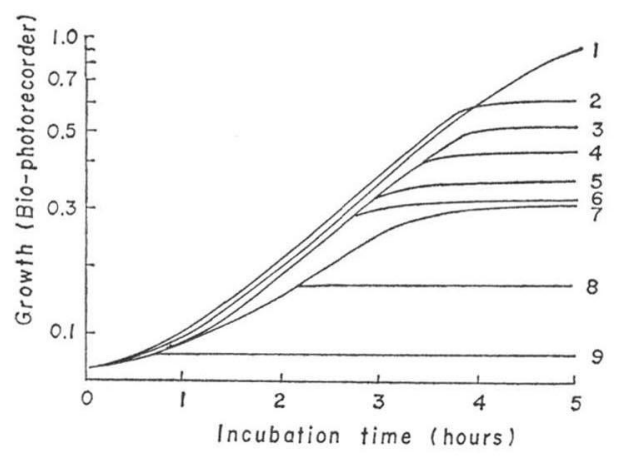

Fig. 3. Viability of E. coli KY 3591 after exposure to $2 \mathrm{AG}$

The incubation of $E$. coli in the presence of $2 \mathrm{AG}$ $(10 \mu \mathrm{g} / \mathrm{ml})$ was performed in test tubes with shaking at $30^{\circ} \mathrm{C}$. Growth was followed by increase in OD (Tokyo Koden Colorimeter with red filter). Viability of $E$. coli was measured by counting colonies on agar plates.

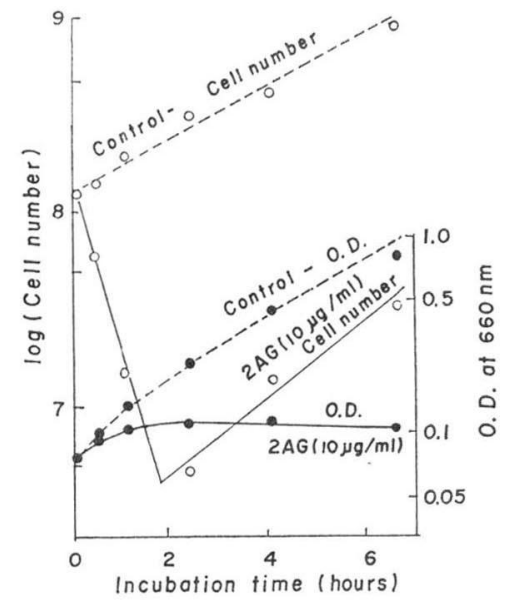

and a purine-requiring mutant of $\mathrm{K}-12$ (KY 8232) were resistant to 2AG. Strain KY 3591 is a prototrophic strain showing growth on the minimum medium and its sensitivity to other drugs such as penicillin G, chloramphenicol, mitomycin $\mathrm{C}$ and 5-fluorouracil is similar to other strains. Since KY 3591 gave a clear growthinhibition zone in contrast to the slightly turbid growth-inhibition zone of KY 8323, further tests were carried out with KY 3591.

The effect of $2 \mathrm{AG}$ on the growth of KY 3591 is shown in Fig. 2. Growth was delayed

by concentration of $0.1 \mu \mathrm{g} / \mathrm{ml}$ and higher. The length of the lag before restoration of growth was dependent on the concentration of $2 \mathrm{AG}$. The addition of more than $10 \mu \mathrm{g} / \mathrm{ml}$ did not further delay the restoration of growth. Organisms arising after prolonged culture in the presence of $10 \mu \mathrm{g} / \mathrm{ml}$ of $2 \mathrm{AG}$ were resistant to 2AG. As shown in Fig. 3, viable counts of KY 3591 dropped for 2 hours after addition of $10 \mu \mathrm{g} / \mathrm{ml}$ of $2 \mathrm{AG}$, although the optical density of the culture remained unaltered after a slight increase in the first 0.5 hour. After 2 hours, viable counts increased due to the growth of resistant clones. From this culture, the resistant strain KY $35912 \mathrm{AG}^{\mathrm{r}}$ was isolated and used for further tests.

Chemically synthesized 2AG-5'-monophosphate (unpublished data) and 2'-amino-2'-deoxyadenosine $^{5)}$ did not show any antibacterial activities.

Effects of Nucleic Acid Related Compounds on Antibacterial Activity of 2AG 
Some nucleoside antibiotics are known to act as metabolic antagonists. ${ }^{4)}$ When the antibacterial activity of a metabolic antagonist is tested in the presence of a competitive metabolite by the agar diffusion method, the diameter of inhibition zone decreases according to the concentration of the competitive metabolite. When guanosine was added to the assay plates of $2 \mathrm{AG}$, the diameter of the growth-inhibition zone did not decrease but the turbidity of the zone did. This result suggested that $2 \mathrm{AG}$ might not act as a metabolic antagonist of guanosine. Thus a detailed study was carried out on the effect of nucleic acid related compounds on the action of $2 \mathrm{AG}$.
Fig. 5. Effect of concentration of guanosine on the antibacterial activity of $2 \mathrm{AG}$

A) growth curves. In the presence of $2 \mathrm{AG}(10 \mu \mathrm{g} / \mathrm{ml})$, guanosine was added at the concentrations indicated in the figure. Incubation was carried out in the Biophotorecorder using the KY 3591 strain. The dotted curve shows the control experiment (without 2AG).

B) Relationship between the concentration of guanosine added to the medium and the level of cell growth after five hours.

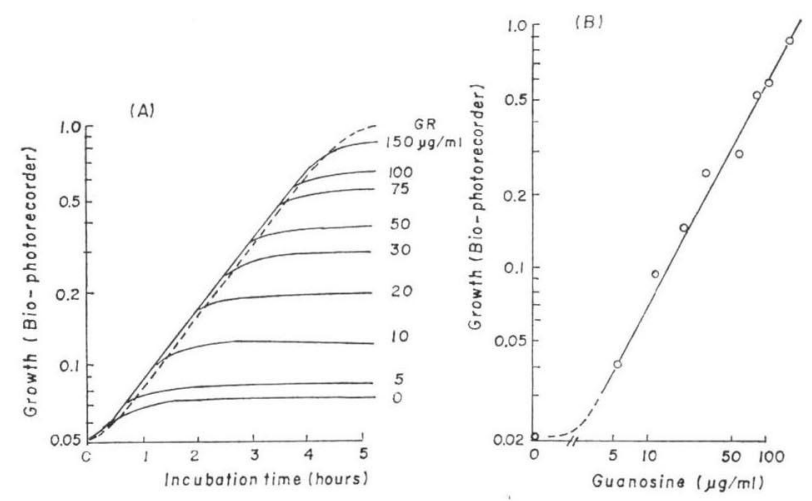

Fig. 6. Effect of addition time of guanosine on the restoration of growth of E. coli KY 3591

Guanosine was added at $100 \mu \mathrm{g} / \mathrm{ml}$ after incubation in the presence of $10 \mu \mathrm{g} / \mathrm{ml}$ of $2 \mathrm{AG}$ for various periods. The growth was followed with the Bio-photorecorder.

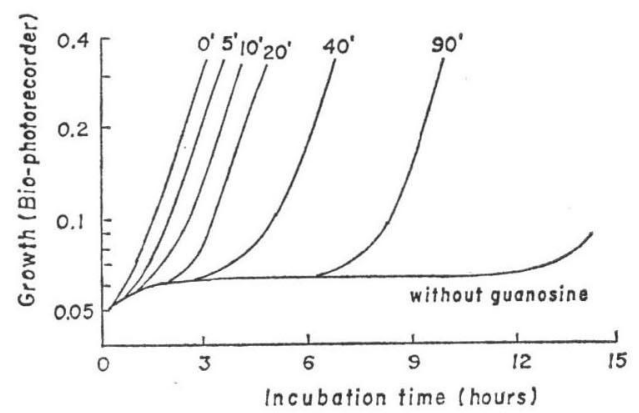

Fig. 7. The inhibitory action of $2 \mathrm{AG}$ on the growth of E. coli KY 3591 in the presence and absence of guanosine

In the presence of guanosine $(100 \mu \mathrm{g} / \mathrm{ml}), 2 \mathrm{AG}$ was added at 1,2 and 3 hours as indicated by arrows $A$, $\mathrm{B}$ and $\mathrm{C}$, respectively. In the absence of guanosine, $2 \mathrm{AG}$ was added at the time of arrows D, E and F. Curve $G$ shows the experiment in which $2 \mathrm{AG}$ was added at 0 time without guanosine. The growth was automatically recorded with the Bio-photorecorder.

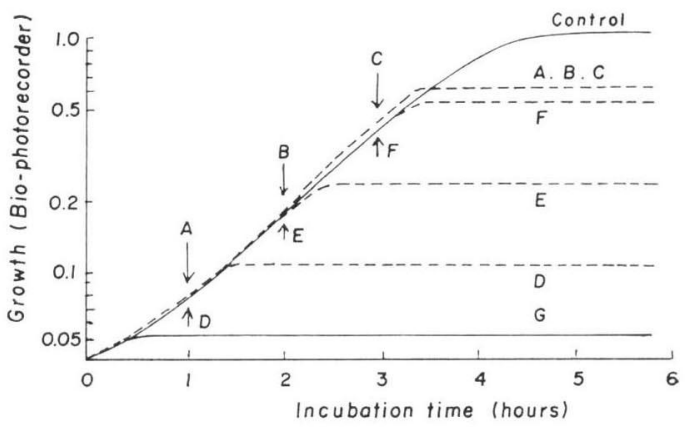

As shown in Fig. 4, purine nucleosides except for xanthosine reversed growth inhibition by $2 \mathrm{AG}$, although the degree of reversal differed depending on the nucleoside. AMP moderately reversed the action of $2 \mathrm{AG}$, while GMP was weak. No activity was shown by IMP, XMP, xanthosine, purine bases, pyrimidine-related compounds, D-ribose, D-2-deoxyribose, D-ribose-5-phosphate, phosphoribosyl pyrophosphate, cyclic AMP and ppGpp. Furthermore it is of interest that the addition of purine 
nucleosides did not affect the growth rate but only the extent of growth.

\section{Effect of Guanosine on the Action of $2 \mathrm{AG}$}

Since guanosine was the most active agent for the reversal of growth inhibition by $2 \mathrm{AG}$, a detailed study of the effects of guanosine was made. In the presence of $2 \mathrm{AG}(10 \mu \mathrm{g} / \mathrm{ml})$, the final growth level increased according to the concentration of guanosine as shown in Fig. 5-A. When the logarithm of the growth level was plotted against the logarithm of concentration of guanosine, the growth level was proportional to the amount of added guanosine in the range of about $10 \sim 100 \mu \mathrm{g} / \mathrm{ml}$

Fig. 8. The incorporation of $2 \mathrm{AG}-8-{ }^{3} \mathrm{H}$ and guanosine-U- ${ }^{14} \mathrm{C}$ into $E$. coli $\mathrm{KY} 3591$ cells

Guanosine and $2 \mathrm{AG}$ were added giving $0.04 \mu \mathrm{Ci} /$ $50 \mu \mathrm{g} / \mathrm{ml}$ and $0.022 \mu \mathrm{Ci} / 10 \mu \mathrm{g} / \mathrm{ml}$ at 0 hour, respectively.

The measurement of $2 \mathrm{AG}-{ }^{3} \mathrm{H}$ incorporation was described in Materials and Methods. The amount of guanosine- $\mathrm{U}-{ }^{14} \mathrm{C}$ and guanine- $\mathrm{U}-{ }^{14} \mathrm{C}$ in the supernatant of the medium was determined after separation by paper chromatography. The growth was measured with Tokyo Koden Colorimeter. (1), Cell growth in the presence of guanosine; (2), cell growth in the absence of guanosine; (3), guanosine-U- ${ }^{14} \mathrm{C}$ in the supernatant of the medium; (4), guanine- $U-{ }^{14} \mathrm{C}$ in the supernatant (the specific activity of guanine is equal to a half of guanosine in radioactivity because the guanine was uniformly labeled); (5), $2 \mathrm{AG}-8-{ }^{3} \mathrm{H}$ incorporated into cells in the presence of guanosine; (6), $2 \mathrm{AG}-8-{ }^{3} \mathrm{H}$ incorporated into cells in the absence of guanosine.
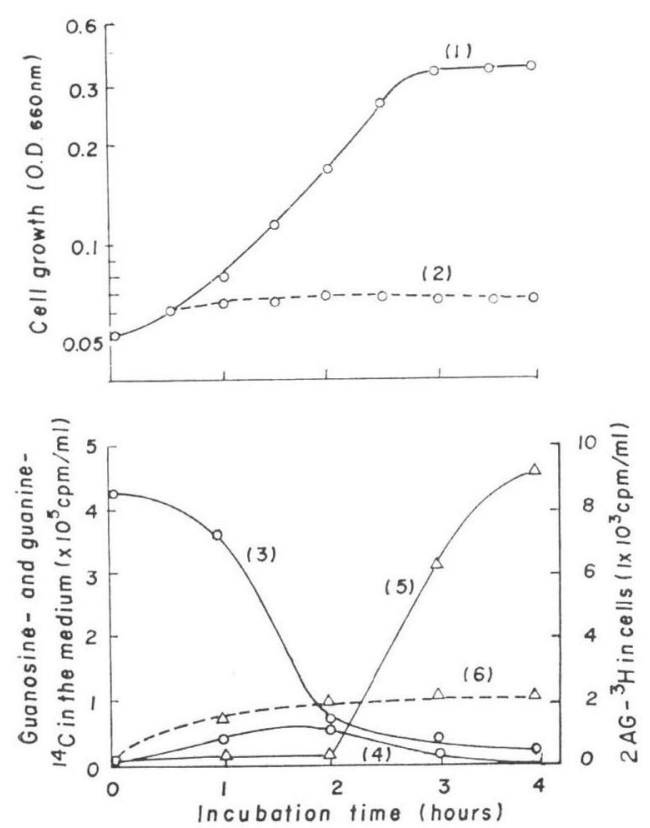

Fig. 9. Effect of guanosine concentration on the 2AG-uptake activity in E. coli $\mathrm{KY} 3591$

Cell suspension of E. coli $\mathrm{KY} 3591\left(10^{8}\right.$ cells $\left./ \mathrm{ml}\right)$ in the medium was incubated at $30^{\circ} \mathrm{C}$ with $2 \mathrm{AG}-{ }^{3} \mathrm{H}$ and guanosine. The reciprocal of incorporation rate was plotted as a function of reciprocal of concentration of $2 \mathrm{AG}$. The incorporation rate was expressed by the radioactivity incorporated per $10^{8}$ cells in 20 minutes.

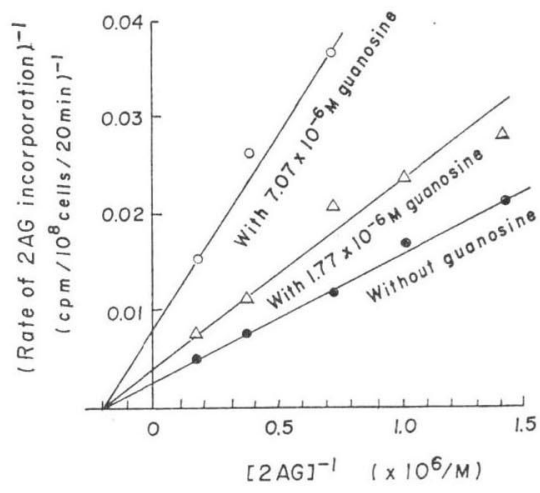

Fig. 10. The uptake of $2 \mathrm{AG}-8-{ }^{3} \mathrm{H}$ by $2 \mathrm{AG}$ resistant strains

To the exponentially growing cultures of $E$. coli strains, $2 \mathrm{AG}$ was added at $0.022 \mu \mathrm{g} / 10 \mu \mathrm{g} / \mathrm{ml}$. The measurement of $2 \mathrm{AG}$ uptake is described in Materials and Methods.

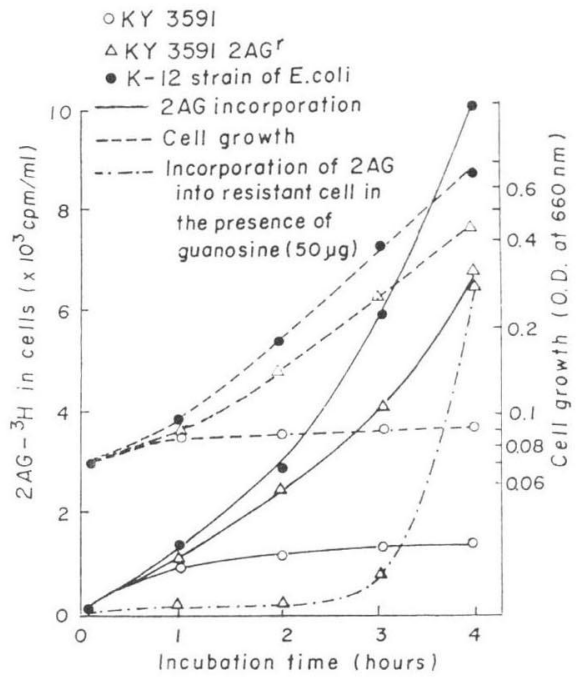


as shown in Fig. 5-B. On the other hand, the effect of concentration of $2 \mathrm{AG}$ on the extent of growth was negligible in the presence of guanosine.

When the addition of guanosine was delayed in the presence of $2 \mathrm{AG}$, the lag time for the restoration of growth was proportional to the delay time (Fig. 6). The time taken for growth to reach an OD of 0.2 was found to be 5 times the delay time. A similar phenomenon was found in an experiment in which washing was used for the elimination of $2 \mathrm{AG}$ instead of addition of guanosine (data not shown).

$2 \mathrm{AG}(10 \mu \mathrm{g} / \mathrm{ml})$ was added after incubation for various periods in the presence of guanosine $(100 \mu \mathrm{g} / \mathrm{ml})$ in order to see whether there is preferential uptake of 2AG. Cell growth consistently stopped at 3.5 hours of incubation despite changes in the addition time of $2 \mathrm{AG}$; in the absence of guanosine, growth always stopped at 30 minutes after the addition of 2AG (Fig. 7). These results indicated that the presence of guanosine above a certain level prevents the uptake of $2 \mathrm{AG}$.

Transport of $2 \mathrm{AG}$ and Guanosine into E. coli

The fate of added guanosine and $2 \mathrm{AG}$ in the medium was investigated by paper chromatography. As shown in Fig. 8, guanosine-U- ${ }^{14} \mathrm{C}$ rapidly decreased to $20 \%$ of the initial amount within 2 hours and guanine increased to $25 \%$ of the initial amount of guanosine. This observation agreed with the result obtained by scanning of the paper chromatogram by UV absorption. The appearance of guanine in the medium suggests that guanosine was transported into the cell by the action of purine nucleoside phosphorylase. ${ }^{8)}$ Guanosine $(50 \mu \mathrm{g} / \mathrm{ml})$ disappeared after $2 \sim 3$ hours and $100 \mu \mathrm{g} / \mathrm{ml}$ of guanosine disappeared by $3 \sim 4$ hours. The uptake of guanosine was not affected by the addition of $2 \mathrm{AG}$.

In the absence of guanosine, $2 \mathrm{AG}-8-{ }^{3} \mathrm{H}$ was immediately transported into the cells and the uptake ceased at about 1 hour because of the inhibition of cell growth. In the presence of $50 \mu \mathrm{g} / \mathrm{ml}$ of guanosine, the uptake of $2 \mathrm{AG}-8-{ }^{3} \mathrm{H}$ began only after incubation for 2 hours. This initiation point of uptake of $2 \mathrm{AG}$ coincided with the time of disappearance of most of the guanosine. The guanine produced in the medium did not appear to affect the transport of $2 \mathrm{AG}$ (see also Fig. 4). These results show that the uptake of $2 \mathrm{AG}$ was prevented by guanosine and only after the reduction of guanosine content was $2 \mathrm{AG}$ transported into the cell.

When $2 \mathrm{AG}-8-{ }^{3} \mathrm{H}$ was taken up by the cells, guanine- $-8{ }^{3} \mathrm{H}$ was not detected in the medium; this was clearly different from the case of uptake of guanosine.

\section{Kinetics of Transport of $2 \mathrm{AG}$}

Tritiated 2AG was taken up linearly into the cell for the first 30 minutes. Because of the low specific radioactivity of $2 \mathrm{AG}^{3}{ }^{3} \mathrm{H}$, the amounts of radioactivity taken up in 20 minutes was used as the rate of uptake. A Lineweaver-Burk plot of uptake of $2 \mathrm{AG}$ is shown in Fig. 9. From this figure, $\mathrm{Km}$ and $\mathrm{V}_{\max }$ were calculated to be $4.0 \times 10^{-6} \mathrm{M}$ and $4.4 \times 10^{-8} \mathrm{~m}$ moles $/ 10^{8}$ cells $/ 20$ minutes, respectively. Guanosine inhibited the uptake of $2 \mathrm{AG}$ non-competitively. The inhibition constant (Ki) was $3 \times 10^{-6} \mathrm{M}$ (guanosine; $\left.7.07 \times 10^{-6} \mathrm{M}\right)$.

\section{Uptake of $2 \mathrm{AG}$ by Resistant and Insensitive Strains}

The transport of $2 \mathrm{AG}-8-{ }^{3} \mathrm{H}$ into resistant strain $\mathrm{KY} 3591\left(2 \mathrm{AG}^{\mathrm{r}}\right)$ and insensitive strain $\mathrm{K}-12$ is shown in Fig. 10. 2AG was taken up as it was by KY 3591 but guanine was not released upon uptake.

It is of interest that guanosine inhibited the uptake of $2 \mathrm{AG}$ by the resistant strain as it did in the sensitive strain KY 3591. 


\section{Discussion}

It has been reported that the antibacterial activity of many nucleoside analogs including nucleoside antibiotics is reversed by the addition of nucleosides or bases. ${ }^{4}$ ) The present study showed that $2 \mathrm{AG}$ acted on only two strains of E. coli KY 8323 and KY 3591 and its action was reversed by the addition of various nucleosides, especially by guanosine. Xanthosine and bases did not reverse inhibition by 2AG. Nucleotides such as AMP and GMP showed moderate or slight reversal but their action could be due to nucleosides produced during incubation.

When guanosine was added to the medium, the final growth level was proportional to the amount of guanosine added. In the presence of guanosine, $2 \mathrm{AG}$ was not transported into the cell and a preferential uptake of guanosine was observed. Guanosine inhibited the uptake of $2 \mathrm{AG}$ non-competitively indicating that $2 \mathrm{AG}$ was taken up through a mechanism different from that of guanosine.

It has been shown that purine nucleosides are transported into $E$. coli by purine nucleoside phosphorylase and purine phosphoribosyltransferases. ${ }^{8)}$ It appears that these enzymes are responsible for transporting guanosine into strain KY 3591, since guanine was released into the medium upon uptake of guanosine. However $2 \mathrm{AG}$ uptake did not result in guanine release. These results suggest the participation of guanosine kinase in the uptake of $2 \mathrm{AG}$, which was recently proposed by JocHIMSEN et al. ${ }^{9}$ )

DIVEKAR et al. ${ }^{10)}$ reported that a subline of mouse sarcoma 180 that is resistant to adenosine analogs showed a 20,000-fold reduction in adenosine kinase, indicating that adenosine kinase was also responsible for the incorporation of analogs. In contrast, $2 \mathrm{AG}$ resistant strain $\mathrm{KY} 35912 \mathrm{AG}^{\mathrm{r}}$ and other resistant strains possessed the ability to take up $2 \mathrm{AG}$ and the uptake of $2 \mathrm{AG}$ was inhibited by guanosine. This observation indicates that the resistance to $2 \mathrm{AG}$ is not due to lack of transport into the cell. In a further study of the action mechanism of $2 \mathrm{AG}$, it has become apparent that $2 \mathrm{AG}$ taken up in the cell is phosphorylated and then incorporated into RNA (in the following paper). Between sensitive and resistant strains, there is a difference in the ability to incorporate $2 \mathrm{AG}$ into RNA.

\section{Acknowledgement}

The authors wish to thank Dr. M. IkeHARA of Osaka University for the gift of 2 '-amino-2'-deoxyadenosine and helpful advise. The authors are grateful to Mr. A. IsHII of Pharmacological Research Laboratory, Fuji plant, Kyowa Hakko Kogyo Co., Ltd. for assistance in the preparation of tritiated $2 \mathrm{AG}$.

\section{References}

1) Nakanishi, T.; T. IIDA, F. Tomita \& A. FuruyA: Identification of a novel aminonucleoside produced by Enterobacter sp. as 2'-amino-2'-deoxyguanosine. Chem. Pharm. Bull. 24: 2955 2960, 1976

2) Nakanishi, T.; F. Tomita \& T. Suzuki: Identification and some culture conditions of $2^{\prime}$-amino-2'deoxyguanosine-producing Enterobacter cloacae. Agr. Biol. Chem. 41: 287 291, 1977

3) Nakanishi, T.; F. Tomita \& T. Suzuki: Production of a new aminonucleoside, 9-(2'-amino-2'-deoxypentofuranosyl)guanine, by Aerobacter sp. Agr. Biol. Chem. 38: 2465 2469, 1974

4) Suhadolnik, R. J.: Nucleoside Antibiotics. Wiley-Interscience, New York, 1970

5) Ikehara, M.; T. Maruyama \& H. Miki: A new method for the synthesis of $2^{\prime}$-substituted purine nucleosides. Total synthesis of an antibiotic 2'-amino-2'-deoxyguanosine. Tetrahedron Lett. -1976: 4485 4488, 1976

6) Hobis, J. B. \& F. Eckstein: A general method for the synthesis of 2'-azido-2'-deoxy-and 2'-amino-2'deoxyribofuranosyl purine. J. Org. Chem. 42: 714 719, 1977

7) Eidinoff, M. L. \& J. E. KNOLL: The introduction of isotopic hydrogen into purine ring systems by catalytic exchange. J. Amer. Chem. Soc. 75: 1992 1993, 1953

8) Hochstadt-Ozer, J.: The regulation of purine utilization in bacteria. IV. Roles of membrane-localized and pericytoplasmic enzymes in the mechanism of purine nucleoside transport across isolated Escherichia coli membranes. J. Biol. Chem. 247: 2419 2426, 1972

9) Jochimsen, B.; P. NygaArd \& T. Vestergatrd: Location on the chromosome of Escherichia coli of genes governing purine metabolism. Molec. Gen. Genet. 143: 85 91, 1975

10) Divekar, A. Y.; M. H. Fleysher, H. K. Slocum, L. N. Kenny \& M. T. Hakala: Changes in sarcoma 180 cells associated with drug-induced resistance to adenosine analogs. Cancer Res. 32: 2530 2537, 1972 